\title{
LA FILOSOFÍA MORAL CARTESIANA Y EL CONTROL HACIA EL SER HUMANO
}

\section{CARTESIAN MORAL PHILOSOPHY AND CONTROL OVER HUMAN BEINGS}

\author{
Diana Solano Villarreal \\ Universidad Nacional de Costa Rica
}

Recibido: 13 de febrero, $2015 \bullet$ Aceptado: 17 de abril, 2015

Ainsi toute la Philosophie est comme vn arbre, dont les racines sont la Metaphysique, le tronc est la Physique, \& les branches qui fortent de ce tronc font toutes les autres sciences, qui fe reduifent à trois principales,à sçauoir la Médecine, la Mechanique \& la Morale, j'entens la plus haute \& la plus parfaite Morale, qui,presuppofant vne entière connoissance des autres sciences, est le dernier degré de la Sagefte ${ }^{1}$

Carta prefacio. Principios de filosofía

Rene Descartes

1 «La totalidad de la Filosofía se asemeja a un árbol, cuyas raíces son la Metafísica, el tronco es la Física y las ramas que brotan de este tronco son todas las otras ciencias que se reducen principalmente a tres: a saber, la Medicina, la Mecánica y la Moral, entiendo por esta la más alta y perfecta Moral, que presuponiendo un completo conocimiento de las otras ciencias, es el último grado de la Sabiduría». 
Resumen: Este artículo presenta un análisis más profundo de la filosofía moral cartesiana en el Discours de la méthode, Les passions de l'âme y en los Principia philosophae, igualmente en la búsqueda de argumentos que hagan evidente alguna relación de control de unos seres humanos sobre otros, y el mecanismo mediante el cual esta hipotética relación de control entre seres humanos se pudiera manifestar.

Palabras clave: filosofía moral, control, Descartes

Abstract: This paper presents a deeper analysis of the Cartesian moral philosophy in the Discours de la méthode, Les passions de l'âme, and the Principia Philosophiae, also in search of arguments to make clear a relation of connection control of some human beings on other, and the mechanism by which this control hypothetical relationship between humans could manifest.

Keywords: Moral philosophy, control, Descartes.

\section{Introducción ${ }^{2}$}

Para comprender mejor a Descartes es necesario remitirnos rápidamente a la época en que vivió y a ciertos hechos que cambiaron el mundo. En el siglo XVI se dieron una serie de eventos que transformaron a Europa hasta nuestros días. La física estaba experimentando enormes cambios, la astronomía moderna estaba naciendo, las técnicas de navegación se estaban revolucionando, la ciencia moderna estaba en gestación. Además con el capitalismo ya en su fase inicial (mercantilismo) se hicieron descubrimientos de nuevas tierras y nuevas gentes al otro lado del Atlántico, cuyos procesos de conquista se vieron relativamente ${ }^{3}$ completados (por lo menos en el caso de los españoles) para mediados del siglo XVI.

Los descubrimientos que se dieron en América transformaron la forma en que Europa veía el mundo para siempre. Luego del descubrimiento del Nuevo Mundo, el mundo medieval se fracturó irremediablemente, para no poder recuperarse jamás.

Descartes nació y vivió en un mundo en conflicto. Por un lado, los modelos medievales estaban en decadencia, pero negándose a morir; y por otro, el mundo moderno luchaba por surgir. En esta lucha Descartes tuvo un papel decisivo, no solo en la conformación de la ciencia moderna, sino también en la consolidación de la modernidad, especialmente en lo que

2 Las citas que aluden a la obra de Descartes aparecidas en el texto pertenecen a la edición en once volúmenes de Adam y Tannery (1964- 1986) y quedan consignadas de la siguiente manera: (A.T., volumen, página; línea).

3 Digo relativamente porque incluso hasta el siglo XX algunos territorios y grupos escaparon del alcance de las estructuras oficiales del poder estatal. 
concierne al conocimiento. Como graduado de la Fleche, Renato Descartes conocía muy bien las características de la escolástica, las razones por las que se encontraba en crisis y la necesidad de crear una alternativa.

No obstante, para crear una posibilidad viable a la filosofía medieval en decadencia, Descartes recurrió a la duda metódica, y por ella tuvo que (tal como lo indicó en el Discours de la méthode) crear una morale par provision que le permitió continuar con su vida, mientras transitó el camino hacia la razón.

La morale par provision constituye casi la totalidad de la filosofía moral cartesiana, la cual no está muy elaborada. De hecho, la morale par provision es un poco más que las cuatro máximas enunciadas y explicadas en la tercera parte del Discours de la méthode.

La filosofía moral de Descartes se basa en su antropología. En Les passion de l'âme se indica que en el alma humana se celebra una lucha constante entre las acciones y las pasiones. Las acciones dependen de la voluntad, mientras las pasiones son involuntarias y están compuestas por percepciones, emociones o sensaciones suscitadas en el alma por los espíritus vitales, es decir, por las fuerzas mecánicas que se dan en el cuerpo. El alma debe tratar, a toda costa, de contener las pasiones y detener los impulsos del cuerpo. Lo anterior no significa que las pasiones sean perniciosas. Las pasiones se dan en el alma y se relacionan con el cuerpo, de manera que el alma debe acceder y colaborar con las acciones que ayudan al perfeccionamiento del cuerpo. Por otra parte, las pasiones no controladas pueden llevar a un estado de servidumbre, del cual el ser humano debe alejarse todo lo que pueda. Para alejarse del desenfreno de las pasiones Descartes recomendó la contención de la voluntad.

En este segundo capítulo siento las bases teóricas que permiten explicar cómo desde la filosofía moral el genio francés del siglo XVII esgrime alguna propuesta de control del ser humano por el ser humano.

\section{La moral provisional en el Discours de la méthode}

A partir de 1637, año de publicación del Discours de la méthode, hasta 1649, el año anterior a su muerte, Descartes no dejó de pensar y expresar sus ideas respecto a la moral; por lo cual me detengo en su obra más conocida, pues resulta indispensable para adelantar en este estudio. 
El Discours de la méthode no es una obra sobre filosofía moral, sino una obra sobre una metodología específica donde se encuentran reflexiones metafísicas, epistemológicas y también morales. Y aunque fue intención y propósito explícito de Descartes el tratamiento de asuntos epistemológicos y metafísicos, se hacen presentes en el Discours los tópicos de carácter moral que alcanzan, en diferente medida, no solo a la tercera y sexta partes, sino a la totalidad de la obra.

El Discours de la méthode, tal como lo indica su título, fue creado para dirigir bien su razón e indagar la verdad en las ciencias. La finalidad de esta obra era la postulación de un método que no presentara los inconvenientes de las filosofías anteriores y que mostrara el camino a la verdad. El método enunciado por Descartes en la obra anteriormente citada fue engendrado en los rigores matemáticos cuyos resultados precisos, según Descartes, dotaban al método de la certeza suficiente para extenderse a otros ámbitos de conocimiento.

Crear una nueva filosofía más cierta que la vulgar requería que Descartes utilizara toda su astucia para llevar a buen puerto su investigación. En este sentido, encarar el asunto de la acción e intentar encontrar alguna salida es imperativo. No es posible esperar a obtener todas las verdades para empezar a actuar. La vida no se detiene, y por ello es prioritario darle al ser humano un rumbo a la conducta lo antes posible.

La moral en el Discours de la méthode es, según Descartes, una moral cuya finalidad es ofrecer seguridad para responder a las exigencias de la vida cotidiana que muchas veces no admiten espera, y orientar hacia la realización de las acciones correspondientes es de gran importancia. La tercera parte del Discours de la méthode comienza de una manera muy interesante

Et enfin, comme ce n'est pas assez, auant de commencer a rebastir le logis oú on demeure, que de l'abattre, et de faire prouision de materiaux et d'Architectes, ou s' exercer soi-mêsme à l'Architecture, et outre cela d'en auoir soigneusement tracé de dessein, mais qu'il faut aussy s'estre pouruu de quelque autre où on puisse estre logé commodément pendant le temps qu'on y trauaillera; ainsi, assin que ie ne demeurasse point irrésolu en mes actions, pendant que la raison m'obligeroit de l'estre en mes iugements, et que ie ne laissassepas de vivre dès lors le plus heureusement que ie pourrois, 
ie me formay vne morale par prouision, qui ne consistoit qu'en trois ou quatre maximes dont je veux bien vous faire $\operatorname{part}^{4}$ (A.T., VI, 22; 16-29).

Descartes era consciente de que la razón lo obligaba a permanecer irresoluto en sus juicios mientras dura ese proceso (y que su duración es indefinida), y como en la vida diaria muchas veces se deben tomar decisiones con celeridad, hay que proveerse de los medios que le permitan atender las urgencias de la vida práctica. Para lo anterior se redactó una morale par provision. Una vez aquí en la tercera parte del Discours, las preocupaciones de corte epistemológico ceden su lugar a las de índole moral.

Dicho en otras palabras, considerando los cuadros de la arquitectura a los que acude Descartes y su misma línea argumentativa, estaba claro para el filósofo francés que los estatutos del método que aseguraban la buena marcha en su búsqueda de la verdad debían estar acompañados de unas máximas morales que le certificaran tranquilidad en su vida.

Mientras la mente se consagra a dudar de todo, la persona como tal debe seguir interactuando en el mundo, por lo que se hizo necesario crear una morale par provision que conduzca la vida. En la tercera parte del Discours el filósofo francés estableció las tres reglas o máximas que él mismo y las personas que quieran seguir la méthode deben practicar mientras se encuentren en el proceso de la duda metódica o la híper duda, como también se le ha conocido. Estas tres máximas constituyen su morale par provision.

Estas reglas o máximas no pretenden ser permanentes. De allí que el mismo Descartes las llamara morale par provision. Ellas son la base de la filosofía moral cartesiana. Esta moral se caracteriza por ser pensada para una acción que no puede ser evidenciada en la práctica, de ahí que el filósofo de Touraine propusiera reglas ensayadas y no decretara leyes. En el texto de la tercera parte del Discours Descartes simplemente enumeró de modo aparentemente escueto sus preceptos de la morale par provision.

4 «Por último, como para empezar a reconstruir el alojamiento en donde uno habita, no basta haberlo derribado y haber hecho acopio de materiales y de arquitectos, o haberse ejercitado uno mismo en la arquitectura y haber trazado además cuidadosamente el diseño del nuevo edificio, sino que también hay que proveerse de alguna otra habitación, en donde pasar cómodamente el tiempo que dure el trabajo, así, pues, con el fin de no permanecer irresoluto en mis acciones, mientras la razón me obligaba a serlo en mis juicios, y no dejar de vivir, desde luego, con la mejor ventura que pudiese, hube de arreglarme una moral por provisión, que no consistía sino en tres o cuatro máximas, que con mucho gusto voy a comunicaros». 
La siguiente exposición pretende analizar las máximas de la morale par provision, llevar a cabo una síntesis de aquellas e indicar desde un primer momento que, así como los preceptos del método son para la razón y no para la voluntad, de igual modo Descartes enunció las máximas morales para la voluntad y no para la razón.

\section{Primera máxima}

La première éstoit d'obéir aux lois et aux coustumes de mon pays, retenant constamment la religion en laquelle Dieu m'a fait la grâce d'estre instruit dés mon enfance, et me gouuernant, en toute autre chose, suivant les opinions les plus moderées, et les plus esloignées de l'excès, qui fus-sent communement recues en pratique par les mieux sensez de ceux avec lesquels j'aurais à viure. Car, commencant dés lors à ne compter pour rien les miennes propres, à cause que je les voulais remettre toutes a l'examen, i'estois assuré de ne pouvoir mieux que de suivre celles des mieux sensés ${ }^{5}$ (A.T., VI, 22; 30 / 23; 1-11). Et, entre plusieurs opinions esgalement receues, ie ne choisissois que les plus moderées: tant à cause que ce sont touiours les plus commodes pour la pratique, et vraysemblablement les meilleures, tous excés ayant coustume d' estre mauuais; comme aussy assin de me détourner moins du vray chemin, en cas que je faillisse, que si, ayant choisi l'vn des extrêmes, c'eust efté l'autre qu'il eust fallu suiure $^{6}$ (A.T., VI, 23; 24-31).

Esta primera máxima se divide en dos partes. En la primera parte Descartes nos dice que debemos obedecer las leyes y costumbres de nuestro país, además de conservar la religión tradicional. En la segunda parte del Discours el filósofo nos dice que «n'y aurait véritablement point d'apparence

5 «La primera fue seguir las leyes y las costumbres de mi país, conservando constantemente la religión en que la gracia de Dios hizo que me instruyeran desde mi infancia, y gobernándome en todas las otras cosas por las opiniones más moderadas y más apartadas de todo exceso, que fuesen comúnmente admitidas en la práctica por los más sensatos de aquellos con quienes tendría que vivir. Porque habiendo comenzado ya a no contar para nada con las mías propias, puesto que pensaba someterlas todas a un nuevo examen, estaba seguro de que no podía hacer nada mejor que seguir las de los más sensatos».

6 «Y entre varias opiniones, igualmente admitidas, elegía las más moderadas, tanto a causa que siempre las más cómodas para la práctica, y verosímilmente las mejores, ya que todo exceso suele ser malo, sino también para alejarme menos del verdadero camino, en caso de error, si, habiendo elegido uno de los extremos, fuese el otro el que debiera seguirse». 
qu'un particulier fît dessein de réformer un État, en y changeant tout dès les fonde-ments, et en le renversant pour le redresser» (A.T., VI, 13; 21-24). ${ }^{7}$

Descartes, como hijo de su tiempo, se adhirió a la realidad social, histórica y política en la cual nació y en ningún momento pensó someterla a examen y menos aún proponer su reforma, por lo menos momentáneamente. Los intereses del filósofo y matemático francés no tenían nada que ver con las reformas externas al individuo, sino con una reforma del conocimiento individual.

La segunda parte de la primera máxima nos dice que la moderación es muy importante, por lo cual estaría influido directamente por Aristóteles y su justo medio. Es posible distinguir hasta aquí tres elementos que bien se pueden considerar como preceptos particulares implicados en la máxima: el primero, la obediencia a las leyes y costumbres del país; el segundo, la religión en la cual Descartes ha sido educado y en la que quiere permanecer; el tercero, la decisión de gobernarse, o comportarse, siguiendo las opiniones de los más sensatos.

El primer precepto se refiere al deseo de Descartes de mantener la tranquilidad necesaria para su trabajo filosófico y científico. Descartes no fue ni pretendió ser un reformador social. El segundo criterio nos habla del deseo del filósofo de no abandonar la religión de su cuna y país. Las dos primeras partes de la primera máxima son sencillas de entender, son un reflejo de la preocupación del filósofo francés por discernir y separar en su pensamiento todos los juicios de los que podía librarse, no solo de sus máximas morales, sino también de «retenant conftanment la religion en laquelle Dieu m'a fait la grâce d'eftre inftruit dés mon enfance»(A.T., VI, 23; 1-3). ${ }^{8}$

El tercer precepto de la primera máxima nos dice que «i’ estois assuré de ne pouuoir mieux que de suiure celles des mieux sensez» (A.T., X, 23; 9-11) ${ }^{9}$. El individuo debe gobernarse de acuerdo con las actuaciones de los más sensatos.

Entre la segunda y tercera parte de la primera máxima queda un espacio o zona gris de acciones y decisiones no contempladas ni por leyes, ni por costumbres, ni por religión. El texto de la máxima es muy patente en la conveniencia de seguir las opiniones y las prácticas más moderadas de los más sensatos, por dos razones: la primera, las prácticas más moderadas son más fáciles de practicar y se evitan los excesos que con frecuencia son

7 En realidad no había posibilidad de que un particular, a propósito hecho de reformar un Estado cambiando todo, desde los fundamentos y en la inversión para enderezar.

8 retener continuamente la religión en la que Dios me dio la gracia de ser instruido en mi infancia

9 estaba seguro de que no podía hacer nada mejor que seguir las de los más sensatos. 
inconvenientes; la segunda, es más fácil reencontrar el camino en caso de extravío cuando se anda por el medio que cuando se transita por uno de los extremos. Es aquí, mientras Descartes busca un punto medio, donde aparece el tercer precepto de la máxima, la libertad:

Et, particulierement, ie mettois entre les excés toutes les promesses par lesquelles on retranche quelque chose de sa liberté. Non que ie desaprouuasse les lois qui pour remedier a l'inconstance des esprits foibles, permettent, lorsqu'on a quelque dessein qui n'est qu' indifferent, qu'on face des vœux des contrats qui obligent a y perseuerer; mais a cause que ie ne voyois au monde aucune chose qui demeurast tousiouis en mesme estat, et que, pour mon particulier, ie me promettois de perfectionner de plus en plus mes iugemens, y non point de les rendre pires, i' eusse pensé commettre vne grande faute countre le bon sens, si pour ce que i' approuuois alors quelque chose, ie me fusse obligé de la prendre pour bonne encore après lorsqu' elle auroit peutestre cessé de l' estre, ou que i' aurois cessé de l'estimer telle ${ }^{10}$ (A.T., X, 24; 1-20).

La libertad hay que aplicarla evitando el camino de los excesos, la cual nos guía en todos aquellos aspectos que están más allá del gobierno de las leyes, las costumbres y de la religión; para lo cual Descartes aconsejó conducirse de acuerdo con «\& me gouuernant, en toute autre chose, suiuant les opinions les plus modérées, $\&$ les plus esloignées de l'excès» (A.T., VI, 23; 3-5) ${ }^{11}$, es decir, las que practican los más sensatos que se pueda encontrar.

Sin embargo, ¿quiénes son esos más sensatos? ¿A quiénes pudo tener en mente el filósofo de Touraine como modelo para su ejemplo? No es sencillo establecer quiénes pudieron ser estos hombres sensatos, ni saber cuáles fueron sus opiniones moderadas. Solo se puede suponer que fue el mismo Descartes quien juzgó entre las opiniones que le rodeaban y optó por las que le parecieron moderadas y más fáciles de seguir, según el tono general de

10 «Y en particular consideraba yo como un exceso toda promesa por la cual se enajena una parte de la propia libertad; no que yo desaprobase las leyes que, para poner remedio a la inconstancia de los espíritus débiles, permiten cuando se tiene algún designio bueno o incluso para la seguridad del comercio, en designios indiferentes, hacer votos o contratos obligándose a perseverancia; pero como no veía en el mundo cosa alguna que permaneciera siempre en idéntico estado y como, en lo que a mí mismo se refiere, esperaba perfeccionar más y más mis juicios, no empeorarlos, hubiera yo creído cometer una grave falta contra el buen sentido, si, por sólo el hecho de aprobar por entonces alguna cosa, me obligara a tenerla también por buena más tarde, habiendo ella acaso dejado de serlo, o habiendo yo dejado de estimarla como tal».

11 y me gobierno en toda otra cosa por las opiniones más moderadas y más apartadas del exceso 
relato de la tercera parte del Discurso. Es el individuo quien decide cuáles son los hombres más sensatos y es él quien decide cuáles son las opiniones más moderadas. El discernimiento es lo que le permite al individuo poner en práctica la primera máxima.

En otras palabras, es el mismo ser humano quien decide mediante actos voluntarios qué toma y qué deja. Lo que sí queda claro es que existen personas a las que debe seguirse o imitarse por la moderación de sus pensamientos y acciones, también existen aquellas que deben dejarse guiar por estas personas más prudentes.

A Descartes no le agradaban los excesos (justo medio aristotélico), y valoró en sumo grado la noción de libertad. Aprobaba la obediencia a las leyes que se promulgan para asegurar el adecuado funcionamiento de los asuntos civiles y para asegurarse que las personas cumplan con sus compromisos.

La libertad para el filósofo francés consistía en preservar la opción de cambiar de rumbo cuando los caminos de la vida así se lo exigieran, cambiar cuando el mundo que lo rodeaba cambiara. Esto último no debe interpretarse como un constante cambio de principios y valores morales en el individuo cada vez que las circunstancias cambien. Significa que si se tiene claro que los seres humanos no tenemos control de nada salvo de nuestros pensamientos, al cambiar las circunstancias en la vida nuestros principios nos ayudarán a mantenernos calmos para afrontar adecuadamente la nueva realidad ante nosotros y optar por una nueva opinión si fuera necesario, en cuanto quede claro que se está en peligro de cometer o se está cometiendo un error.

Descartes quería ejercer su libertad perfeccionando cada vez más sus pensamientos. La libertad que Descartes enunció en esta máxima es muy restringida: conservar su opción de cambiar de opinión cuando los hechos de un mundo cambiante lo hacen necesario. Lo anterior nos lleva a la siguiente cuestión: ¿Cuál es la intención de la primera máxima? ¿Adaptarse a las circunstancias? Parece que sí. Por eso, donde hayamos de vivir, según su modo de vida, de ese modo tenemos que conducirnos. Pues en ese lugar ni sus leyes, ni sus costumbres, ni su tipo de gobierno, ni su cosmovisión, dependen de nosotros. 


\section{Segunda máxima}

Ma seconde maxima estoit d'estre les plus ferme et plus resolu en mes actions que ie pourrois, y de ne suiure pas moins constanmente les opinions les plus douteuses, lorsque ie m' y serois vne fois determiné, que si elles eussent esté tres assurées. Imitant en cecy les voyasgeurs qui, se trouuant esgarez en quelque forest, ne doiuent pas errer en tournoyant, tantost d' vn costé, tantost d' vn autre, ny encore moins s' arester en vne place, mais marcher tousiours le plus droit qu'ils peuuent vers vn mesme costé, et ne le changer point pour de foibles raisons, encore que ce n'ait peutestre esté au commencement que le hasard seul qui les ait determinez a le choisir ; car, par ce moyen s'ils ne vont iustement ou ils desirent, ils arriueront au moins a la fin quelque part, où vraysemblablement ils seront mieux que dans le milieu d' vne forest ${ }^{12}$ (A.T., VI, 24; 17-31, 25; 1-2).

Esta segunda máxima nos dice que el individuo debe mantenerse firme en las decisiones que toma, aun cuando haya dudas sobre estas, y tomarlas como verdaderas. Como la vida rara vez ofrece certezas y la mayoría del tiempo se debe actuar con falta de elementos definitivos y seguros, es importante aferrarse a los principios que se han elegido. La influencia estoica es especialmente clara en esta máxima. La firmeza de las normas morales es un elemento típicamente estoico y la proclama de la conformidad con la naturaleza para vivir feliz. También creían que la naturaleza hizo al hombre bueno, por tanto, aquello que sucedía por decisión de natura se debía aceptar tal cual.

En los primeros renglones de la segunda máxima ${ }^{13}$ se presenta la idea básica de mantener la firmeza en las acciones una vez tomada la respectiva decisión. La irresolución es uno de los temas importantes tratados por Descartes. Escribió:

12 «Mi segunda máxima fue la de ser en mis acciones lo más firme y resuelto que pudiera y seguir tan constante en las más dudosas opiniones, una vez determinado a ellas, como si fuesen segurísimas, imitando en esto a los caminantes que, extraviados por algún bosque, no deben andar errantes dando vueltas por una y otra parte, ni menos detenerse en un lugar, sino caminar siempre lo más derecho que puedan hacia un sitio fijo, sin cambiar de dirección por leves razones, aun cuando en un principio haya sido sólo el azar el que les haya determinado a elegir ese rumbo; pues de este modo, si no llegan precisamente adonde quieren ir, por lo menos acabarán por llegar a alguna parte, en donde es de pensar que estarán mejor que no en medio del bosque».

13 Aquí se establece una relación con la primera máxima, pues en la decisión de Descartes de obedecer las leyes y costumbres del país y atenerse a las opiniones de los más sensatos, así como examinar las opiniones recibidas, se encuentra una firme y constante decisión. 
Ma seconde maxima estoit d' estre les plus ferme et plus resolu en mes actions que ie pourrois, y de ne suiure pas moins constanmente les opinions les plus douteuses, lorsque ie m' y serois vne fois determiné, que si elles eussent esté tres assurées ${ }^{14}$ (A.T., VI, 24; 17-22).

Descartes tomó esta decisión de aferrarse a una opinión dudosa; cuando las circunstancias nos obligan a decidir en el acto y al no encontrar una alternativa mejor, se actúa siguiendo las opiniones dudosas como si fueran verdaderas. Una vez que se toma la decisión, hay que aferrarse a ella hasta que de alguna manera quede claro que el individuo se encuentra en un error. Para exigirse de manera inquebrantable y resuelta en sus acciones una vez que se ha decidido por ellas.

Descartes tomó como ejemplo a los viajeros cuando se pierden en algún bosque. Un viajero que se encuentra perdido en un bosque tiene la inmediata necesidad de volver a orientarse y salir del follaje, lo cual exige una decisión firme e inquebrantable de perseverar en las acciones elegidas como único medio de evitar la vacilación y lograr, de ese modo, salir de la oscuridad el bosque. Así como para el viajero perdido en el bosque, en la vida cotidiana hay muchas decisiones que además de ser importantes no admiten demora. Descartes sabía que la vida no se iba a detener mientras él construía su nuevo conocimiento, por eso en ocasiones hay que actuar rápido, esperando que la opción que se escogió sea la correcta.

Dicho de otro modo, lo que da pleno sentido a la segunda máxima es la vida diaria y sus urgencias, lo que hace que la segunda máxima sea necesaria es la imposibilidad (en muchas ocasiones) de aplazar ciertas decisiones que se deben tomar y seguir con resolución y firmeza.

Descartes sabía que al momento de escoger una opción para distinguir las opiniones verdaderas de las falsas debemos valorar las más probables. No obstante, el hecho de que una decisión sea impostergable no significa que no deba ser reflexionada y razonada. Para establecer cuál de las opciones se debe escoger de acuerdo con su verosimilitud, se debe establecer una probabilidad y esto se hace con la razón. Esta razón es la que dota de firmeza a los fuertes motivos que tuvo la voluntad para elegir lo que consideró lo mejor.

14 «Mi segunda máxima fue la de ser en mis acciones lo más firme y resuelto que pudiera y seguir tan constante en las más dudosas opiniones, una vez determinado a ellas, como si fuesen segurísimas». 
Lo más viable y más probablemente exitoso entre las opiniones disponibles, tal como lo prescribe la máxima. En la parte final de la máxima el filósofo le indica al lector el motivo que lo ha llevado a proponer la segunda máxima:

Et cecy fut capable dés lors de me deliurer de tous les repentirs y les remors, qui ont costume d'agiter les consciences de ces espris foibles et chancelans, qui se laissent aller inconstanment a pratiquer comme bonnes, les choses que qu' il iugent mauuaises ${ }^{15}$ (A.T., VI, 25; 14-19).

Así, Descartes mediante el cumplimiento de la segunda máxima se garantizó evitar las constricciones, las pesadumbres y la pena del alma (estados del alma típicos en espíritus débiles y vacilantes), cosa que le preocupaba mucho, puesto que lo alejaba de su ideal de felicidad.

Lo que Descartes pretendía con la segunda máxima no era criticar la concepción, o las determinaciones de los espíritus, sino la actitud vacilante de los espíritus débiles que modifican sus decisiones por motivos fútiles, y les lleva muy constantemente a esos estados que afligen al alma y que tanto le preocupaban al filósofo francés.

¿Qué es lo fundamental en la segunda máxima referente a la morale par provision? La idea fundamental expresada en la primera frase de la máxima: «Être plus ferme et décidé qu'il pourrait mes actions» ${ }^{16}$ (A.T.,VI, 24; 17) siguiendo las opiniones más probables, a la luz de la razón, para que se puedan evitar los arrepentimientos y los remordimientos, que tanto torturan al alma.

\section{Tercera máxima}

Ma troisiesme maxime estoit de tascher tousiours plutost a me vaincre que la fortune, \& a changer mes desirs que l'ordre du monde, et generalement de m'accoustumer a croire qu'il n'y a rien qui soit entierement en nostre pouuoir que nos pensées, en sorte qu'aprés que nous auons fait nostre mieux

15 «Y esto fue bastante para librarme desde entonces de todos los arrepentimientos y remordimientos que suelen agitar las consciencias de esos espíritus endebles y vacilantes, que se dejan ir inconstantes a practicar como buenas las cosas que luego juzgan malas».

16 Ser más firme y decidido que pudiera en mis acciones. 
tou chant les choses qui nous sont exterieures, tout ce qui manque de nous reussir est au regard de nous absolument impossible ${ }^{17}$ (A.T., VI, 25; 20-28).

La tercera máxima está evidentemente influenciada por Séneca. Debemos dominar aquello que está a nuestro alcance: el pensamiento. No desear lo que no podemos alcanzar, pues al no conseguirlo nos encaminamos hacia la infelicidad. No es conformismo, es saber reconocer nuestra situación y nuestros límites.

Por otro lado, el racionalismo cartesiano sale a la luz cuando se nos dice que la razón es suficiente para que el individuo busque los bienes que debe perseguir, y también cuando dice que la virtud es solo el razonamiento correcto que debe guiar nuestras acciones.

\section{La filosofía moral en Les passions de l'âme}

Descartes publicó el año antes de su muerte el libro Les passions de l âme, (A.T, XI) donde expone que las pasiones del alma son fundamentalmente el resultado de la influencia de ciertos movimientos del cuerpo y de cierta actividad del alma sobre la glándula pineal. Empero, en el Artículo CXLIV está claro que más allá de la mera estimulación de la glándula pineal y las pasiones, la moral también consiste en cómo regular nuestros deseos, en controlar nuestra voluntad y en poder distinguir de manera suficiente «les choses qui dépendent entièrement de nous de ceux qui ne sont pas dépendants $^{18}$ » (Artículo CXLIV, A.T., XI, 436; 24-25).

\section{Primera parte}

En la primera parte, en el Artículo XXVII, Descartes se ocupa de las percepciones del alma que no son más que pensamientos y trata de definirlas en varios momentos. Descartes definió las pasiones del alma de la siguiente forma:

17 «Mi tercera máxima fue procurar siempre vencerme a mí mismo antes que a la fortuna, y cambiar mis deseos antes que el orden del mundo, y generalmente acostumbrarme a creer que nada hay que esté enteramente en nuestro poder que nuestros propios pensamientos, de suerte que después de haber obrado lo mejor que hemos podido, en lo tocante a las cosas exteriores, todo lo que falla en el éxito es para nosotros absolutamente imposible».

Las cosas que dependen enteramente de nosotros de los que no son dependientes. 
Apres avoir confideré en quoy les passions de l'ame différent de toutes ses autres pensées, il me semble qu'on peut generalement les définir: Des perceptions, ou des sentimens, ou des émotions de lame, qu'on raporte particulièrement à elle, $\&$ qui sont causées, entretenuës $\&$ fortifiées par quelque mouvement des esprits ${ }^{19}$ (Artículo XXVII, A.T., XI, 349; 9-16).

En el Artículo XXVIII el genio francés nos aclara a qué se refiere con la palabra perception:

On les peut nommer des perceptions, lors qu'on se sert généralement de ce mot, pour signifier toutes les pensées qui ne sont point des actions de l'ame, ou des volontez; mais non point lors qu'on ne s'en sert que pour signifier des connoissances evidentes $^{20}$ (A.T., XI, 349; 19-23).

No obstante, lo fundamental nos lo dice Descartes en el Artículo XXX: «Que l'ame est véritablement jointe à tout le corps» ${ }^{21}$ (A.T., XI, 351; 5-6) y no a alguna de sus partes: «À cause quelle est d'une nature qui n'aaucun raport à l' estendue, ny aux dimensions, ou autres proprietez de la matiere dont le corps est composé, mais seulement à tout l' assemblage de ses organes» ${ }^{22}$ (A.T., XI, 351; 12-16).

Ahora bien, ¿cómo se produce una pasión? Según el Artículo XXXI, se da mediante la unión desigual del alma y el cuerpo, es decir, de forma más marcada en unas partes que en otras, por eso:

Examiner attentivement la chose, il me semble avoir reconnu clairement que la partie du corps qui exerce ses fonctions immédiatement n'est nullement le cœur, ni dans le cerveau, mais seulement le plus intime de ces pièces, qui est une certaine très petite glande située au milieu de sa substance et ainsi suspendus au-dessus du canal par lequel les esprits de leurs cavités antérieures

19 «Después de haber considerado en qué difieren las pasiones del alma de todos los demás pensamientos de la misma, creo que se pueden generalmente definir dos percepciones, o los sentimientos, o las emociones del alma, que se refieren particularmente a ella, y que son causadas, sostenidas y fortificadas por algún movimiento de los espíritus.

20 «Podemos llamarlas percepciones cuando empleamos en general esta palabra para designar todos los pensamientos que no son acciones del alma o voluntades, pero no cuando la usamos para designar conocimientos evidentes.

21 «Que el alma está verdaderamente unida a todo el cuerpo».

22 «A causa que el alma es de una naturaleza que no tiene relación alguna con la extensión ni con las dimensiones o con otras propiedades de la materia de que el cuerpo se compone, sino solamente con todo el conjunto de sus órganos». 
sont coupées à l'arrière, ses moindres mouvements ont un grand pouvoir de changer le cours de ces esprits et, inversement, que les plus petits changements qui se produisent dans le cours des esprits ont un grand pouvoir de changer les mouvements de cette glande ${ }^{23}$ (Artículo XXXI, A.T., XI, 352; 6-21).

La sede del alma es la glándula pineal, como lo afirma claramente Descartes en el Artículo XXXII: «L' ame ne peut avoir en tout le corps aucun autre lieu que cette glande, où elle exerce immédiatement ses fonctions ${ }^{24}$ (A.T., XI, 352; 25-27). Las marcas de los objetos externos son llevadas por los espíritus animales a esta pequeña glándula en el cerebro desde donde esta irradia a todo nuestro cuerpo.

Las pasiones de los seres humanos son poderosas, tan poderosas que si simplemente nos dejáramos llevar por ellas nos sentiríamos muy cómodos, pero de seguro incurriríamos en una gran cantidad de errores. La fórmula para evitar un buen porcentaje de errores es acudir a la fuerza de la voluntad. Desde luego, esto implica un fuerte combate entre la fuerza de las pasiones y la fuerza de la voluntad, pues:

La petite glande dans le milieu du cerveau, et comment il peut être poussé d'un côté par l'âme, et l'autre par les esprits animaux comme déjà dit, sont des corps, il arrive souvent que ces deux impulsions sont contraire et que l'effet le plus fort empêche les autres ${ }^{25}$ (Artículo XXXI).

Cuando se llega al Artículo XLVIII se puede encontrar una importante afirmación, pues se revela que la manera de conocer «la une ou la faiblesse des âmes» ${ }^{26}$ (Artículo XLVIII, A.T., XI, 366; 25) es precisamente donde se

23 «Examinando atentamente la cosa, paréceme haber reconocido claramente que la parte del cuerpo en la que el alma ejerce inmediatamente sus funciones no es en modo alguno el corazón, el cerebro, sino solamente la más interior de sus partes, que es cierta glándula muy pequeña, situada en el centro de su sustancia y de tal modo suspendida sobre el canal por el cual se comunican los espíritus de sus cavidades anteriores con los de la posterior, que los menores movimientos que se producen en esta tienen un gran poder para cambiar el curso de estos espíritus, y recíprocamente, los menores cambios que se producen en el curso de los espíritus lo tienen igualmente para variar los movimientos de esta glándula».

24 «El alma no puede tener en todo el cuerpo ningún otro lugar que esta glándula donde ella ejerce inmediatamente sus funciones».

25 «La pequeña glándula en el centro del cerebro, y cómo puede ser empujado a un lado por el alma, y el otro por los espíritus animales como ya se dijo, son cuerpos, a menudo sucede que estos dos impulsos son opuestos y que el efecto más fuerte impide que otra»

26 «La una donde la debilidad de las almas». 
hace evidente la contienda entre la voluntad y las pasiones: «Pour ceux qui seront naturellement plus facile à surmonter les passions et arrêter les mouvements du corps qui les accompagnent, ont sans aucun doute les âmes les plus fortes» ${ }^{27}$ (Artículo XLVIII, A.T., XI, 366; 26-29; 367, 1).

Descartes nos dice que las almas tienen armas, y estas armas propias de la voluntad: "Les jugements claires et décisives concernant la connaissance du bien et du mal, après quoi elle a décidé de mener les actions de sa vie» ${ }^{28}$ (A.T., XI, 367; 6-9).

Algo muy diferente les ocurre a las almas débiles, pues su voluntad vacilante no se logra decidir por ningún juicio: «Mais continuellement emporté par les passions du moment», ${ }^{29}$ (A.T., XI, 367; 10-11) las cuales suelen ser contradictorias entre sí, la halan de un lado para otro y la incitan a luchar contra sí: «Incitation à lutter contre lui-même, mis l'âme dans le plus déplorable qu'elle peut l'être».30 (A.T., XI, 367; 15-16)

En este punto sobresale de manera especial la reflexión en torno a la fuerza y la debilidad de las almas. Experimentar las pasiones es parte de la naturaleza del ser humano, el vigor o la astenia del alma para oponerse a esas pasiones también es natural y variará de individuo a individuo. Tal como se dijo en la página anterior, para Descartes las almas tenían armes para que la voluntad controlara las pasiones en función de una decisión eminentemente moral: «conduire les actions de sa vie». ${ }^{31}$ (A.T., XI, 367; 8-9)

La determinación es una de las grandes armas de las almas, y solo hace su aparición cuando el sujeto moral se ve precisado a no dejarse dominar por las pasiones y a utilizar las defensas que posee la voluntad para conocerlas y controlarlas en función del bien y de la conducción adecuada de la vida.

En cuanto al control de las pasiones, lo mejor que se puede hacer es entenderlas a fondo para ayudarse a controlarlas y ponerlas al servicio del individuo, no olvidando que si algo se encuentra por completo al alcance del poder de la persona.

27 «Por propio impulso vencer más naturalmente las pasiones y detener los movimientos del cuerpo que las acompañan tienen sin duda las almas más fuertes».

28 «Juicios claros y decisivos concernientes al conocimiento del bien y del mal con arreglo a los cuales la voluntad ha decidido conducir las acciones de su vida».

29 «Pero continuamente se deja llevar por las pasiones del momento».

30 «Incitándola a luchar contra sí misma, colocando al alma en lo más deplorable que ella pueda estar».

31 «Conducir los actos de su vida». 


\section{Segunda parte}

La segunda parte de Les Passion de l'âme trata de «le nombre et l'ordre des passions, et l'explication des six primitives». ${ }^{32}$ (A.T., XI, 371).Aquí haré énfasis en los inconvenientes de los excesos y el buen uso de la razón para evitarlos. En el Artículo CXXXVIII se expresa que: «Nous dervons nous expérience et de la raison, de distinguer le bien du mal et de savoir sa vraie valeur, afin de ne pas prendre l'un pour l'autre et rien enclin à l'excès» ${ }^{33}$ (A.T., XI, 431; 23-27).

En el artículo CXLIV hace su aparición el tema de las preocupaciones abiertamente morales:

Mais pource que ces Passions ne nous peuvent porter à aucune action, que par l'entremise du Desir qu'elles excitent, c'est particulièrement ce Desir que nous devons avoir foin de régler; \& c'est en cela que consiste la principale utilité de la Morale ${ }^{34}$ (A.T., XI, 436; 14-18).

Con los deseos se debe evitar un error muy común: no distinguir lo suficiente las cosas que dependen enteramente de nosotros de aquellas que no dependen, para evitar caer en excesos.

Ahora, sí existe un remedio infalible contra los excesos: «La vertu de Generosité, laquelle estant comme la clef de toutes les autres vertus, \& un remède gêneral contre tous les dereglemens des Passions» ${ }^{35}$ (A.T., XI, 454; 6-8) y trata sobre todo del control de las pasiones, de tal manera que sí es el deseo incitado por ellas lo que debe controlar el sujeto moral en atención a las cosas buenas que dependen de él, es su voluntad. Por ello, el papel principal de la moral será ejercer adecuadamente el libre arbitrio que, en este caso particular, se traduce, una vez más en la posibilidad de llevar a cabo un control de las pasiones. De acuerdo con el artículo CXLVI: «Facilement pris l'habitude de régler les désirs de telle manière que, si la conformité ne

32 «El número y el orden de las pasiones, y la explicación de las seis primitivas».

33 «Necesitamos experiencia y de la razón, de distinguir el bien del mal y de saber su verdadero valor, para no tomar lo uno por lo otro y no inclinarse a los excesos».

34 «Pero, como estas pasiones no nos pueden llevar a ninguna acción sino por medio del deseo que suscitan, es particularmente este deseo lo que debemos cuidamos de regular; y en esto consiste la principal utilidad de la moral».

35 «La virtud de la generosidad, y como esta es la clave de todas las demás virtudes y un remedio general contra los desórdenes de las pasiones». 
dépend que de nous, ils peuvent toujours nous donner satisfaction ${ }^{36}$ (A.T., XI, 440; 14-17).

Descartes terminó la segunda parte de Les passions de l'âme indicando que «l'exercice de la vertu est un remède souverain contre les passions» ${ }^{37}$ (Artículo CXLVIII), pues según el filósofo y matemático francés, quien quiera que haga siempre lo que juzgue mejor de manera que su conciencia no tenga nada que reprocharle: «Reçoit une satisfaction, qui est si puissante pour le rendre heureux, que les plus violens effors des Passions n'ont jamais assez de pouvoir pour troubler la tranquillité de son ame» ${ }^{38}$ (A.T., XI, 442; 14-17). Debe tenerse en cuenta que hacer siempre lo que se juzgue como lo mejor corresponde precisamente a lo que Descartes consideraba como la virtud.

\section{Tercera parte}

La tercera parte de Les passions de l'âme no será examinada, en tanto la generosidad, pasión capital para el desarrollo de esta tesis, ya que fue expuesta anteriormente. No obstante, mencionaré brevemente su estructura. La tercera parte de la obra se subtitula «Des passions particulières». Luego de explicadas las seis pasiones primitivas, Descartes quiso explicar los géneros a los cuales pertenecen las pasiones y comenzó por la estima y el menosprecio (Arts. CXLIX a CLI).

Después se trata el tema del libre arbitrio como la única cosa que justifica que nos estimemos, para ocuparse inmediatamente después de la definición de la generosidad, que se puede considerar como indiscutible núcleo moral de esta parte del tratado, que ocupa un importante número de artículos (Arts. CLIII a CLXI).

Expuesta la generosidad, pasó a ocuparse en los dos artículos siguientes de dos pasiones particulares, la veneración y el desdén (Arts. CLXII y CLXIII), para llegar de nuevo a la generosidad y la debilidad de espíritu como determinantes de las dos pasiones anteriores (Artículo CLXIV) y ocuparse enseguida de la irresolución, que no es una pasión, pero en cambio

36 «Fácilmente tomando el hábito de regular los deseos de esta manera que si la conformidad no depende de nosotros, ellos pueden siempre darnos satisfacción».

37 «El ejercicio de la virtud es un remedio soberano de las pasiones».

38 «Recibe una satisfacción tan poderosa para hacerle feliz que ni los más violentos esfuerzos de las pasiones tienen jamás bastante poder para turbar la tranquilidad de su alma». 
sí tiene una muy fuerte connotación moral (Artículo CLXX), para concluir la tercera parte y Les passions de l'âme con el Artículo CCXII: "Cela dépend de passions tout le bien ou le mal de cette vie». ${ }^{39}$

El control de las pasiones es fundamental en la filosofía moral cartesiana, sobre esto hay un consenso indiscutible entre los académicos. Si el individuo no controla sus pasiones, nunca podrá tener beatitud, en pocas palabras, no podrá ser feliz.

\section{La filosofía moral en los Principia Philosophae}

Siete años después de la publicación del Discours de la méthode (1637) salió a la luz la edición en latín de los Principia philosophae (A.T., VIII).en 1644, la cual no contiene la célebre «Carta prefacio». No fue sino hasta 1647 que se publicó la versión francesa, esta ya con la «Carta prefacio». Los Principia es una obra muy interesante que en principio Descartes no pensó para una gran audiencia, por eso la escribió en latín. Tan es así que la traducción francesa no fue realizada por el filósofo francés, sino por el abate Claude Picot, aunque sí revisada por el filósofo de Turaine. Empero, en la carta prefacio dejó muy claras sus intenciones respecto al reducido público para quien fue dirigida la obra.

Los Principia philosophiae presentan las líneas generales de la filosofía cartesiana y sus investigaciones, lo cual no es de gran interés para el presente trabajo. Sin embargo, lo que sí tiene especial importancia para esta investigación es el desarrollo del tema moral en la «Carta prefacio» ${ }^{40}$ que acompaña a la obra. En esta carta el filósofo francés realizó una fastuosa explicación de lo importante de la nueva filosofía en la que estaba trabajando, cuya meta era un vasto concepto de sabiduría.

Ainsi toute la Philosophie est comme vn arbre, dont les racines sont la Metaphysique, le tronc est la Physique,\& les branches qui fortent de ce tronc sont toutes les autres sciences, qui se reduisent à trois principales, à sçauoir la Médecine, la Mechanique \& la Morale, j'entens la plus haute $\&$ la plus

39 «De las pasiones depende todo el bien o el mal de esta vida».

40 Esta carta se presenta en francés porque pertenece a la primera edición en francés (Les principes de la philosophie, 1647), en París, a cargo de Henri Le Gras. La traducción del abate Picot fue revisada por Descartes, quien añadió la célebre «Carta prefacio». 
parsaite Morale, qui, presupposant vne entière connoissance des autres sciences, est le dernier degré de la Sagesse ${ }^{41}$ (A.T. IX, 312; 23-31).

La moral ocupa el sitio más importante en la concepción de sabiduría cartesiana, la cual para ser alcanzada necesita del aporte constante de las ciencias. Descartes no desarrolló su filosofía moral en los Principia, él esperaba hacerlo en trabajos posteriores. Para Descartes la sabiduría significaba la unión del conocimiento y del arte de vivir, no uno divorciado del otro. La razón, el conocimiento y la moral deben vivir juntos.

Es muy interesante que aun cuando Descartes nos ha dejado claro en el Discours de la méthode que, aunque muchas veces en la vida no tenemos certeza absoluta de que la decisión que hemos tomado sea de hecho la correcta, debemos continuar con ella, pues al tener que adoptar las decisiones cotidianas generalmente no nos dará tiempo de pensar mucho. Tanto en el mismo Discours como luego en la «Carta prefacio», en esta última más claramente, expresó que las decisiones de la vida también pueden variar si aparece una razón de peso para hacerlo.

En la «Carta prefacio» el filósofo de La Haye de Touraine nos explica que la morale par provision no es una moral «acabada» y que espera en el futuro perfeccionarla:

La première partie de ces essais fut vn Difcours touchant la Méthode pour bien conduire sa raison \& chercher la vérité dans les sciences, où je mis fomjmairement les principales règles de la Logique \& d'vne Morale imparfaite,qu'on peut suiure par prouision pendant qu'on n'en sçait point encore de meilleure ${ }^{42}$ (A.T., IX-2, 15; 9-15).

No obstante, no debemos pensar que la morale par provision del Discours fue desechada por Descartes en la «Carta prefacio». Con ella se pretendía proporcionar una salida práctica para las incertidumbres de la

41 «La totalidad de la Filosofía se asemeja a un árbol, cuyas raíces son la Metafísica, el tronco es la Física y las ramas que brotan de este tronco son todas las otras ciencias que se reducen principalmente a tres: a saber, la Medicina, la Mecánica y la Moral, entiendo por esta la más alta y perfecta Moral, que presuponiendo un completo conocimiento de las otras ciencias, es el último grado de la Sabiduría».

42 «La primera parte de estos ensayos fue un Discurso sobre el Método para conducir bien la razón y buscar la verdad en las ciencias, en las que puse sumariamente las principales reglas de la lógica y de una moral imperfecta, que puede ser seguida por provisión mientras todavía no conocemos el mejor punto». 
vida, sobre las cuales no tenemos ningún control. La morale par provision proporciona una orientación para guiarse lo mejor que se pueda en la vida mientras la persona se encuentra en el camino de la duda metódica.

Lo más importante de la «Carta prefacio» es que en ella se deja clara la gran importancia que tenía para su autor la cuestión moral y la conexión que tiene con la sabiduría de los individuos, que pretendían alcanzar la verdad. Desde luego, tal como se puede apreciar en este capítulo, no es suficiente querer conocer la ciencia y la verdad, para esto hace falta poseer un fuerte control de la voluntad.

La falta de control de la voluntad de las personas de espíritu débil las vuelve vulnerables no solo ante los accidentes de la vida, sino ante otros individuos que por muchas razones tienen en sus manos la fortuna de estos espíritus débiles. Los espíritus débiles se volverán serviles de quienes tienen su suerte en sus manos e indiferentes y hasta crueles con quienes no influyen en nada en su vida. El servilismo del espíritu débil llega a tal punto que se pueden volver legítimos títeres de quienes les pueden brindar algún beneficio.

El carácter de los espíritus endebles los vuelve excelentes candidatos para ser apoyados, orientados y guiados para que logren su libertad de la fortuna. Aprender a controlar la voluntad para liberarse de la tiranía del destino sería, según la filosofía moral cartesiana, un gran bien.

No obstante, aprender por los propios medios la templanza y el control de las pasiones no es fácil. El filósofo francés lo sabe y por ello nos habla de la utilidad y eficiencia de la educación para estos menesteres.

Ahora bien, en las relaciones de educación incluso hoy se da un cierto nivel de control del maestro hacia el alumno, por más amable y respetuoso que este sea, siempre deberá ejercer algún control sobre su discípulo. Lo crítico de esta situación no es el control en sí mismo, pues la horizontalidad en la educación ha estado presente prácticamente desde siempre. Lo importante de este control en Descartes es el motivo por el que se justifica (tácitamente) este control.

El maestro no lo es solo porque se le haya designado para tal labor, debe poseer varias características intelectuales (las cuales se explicarán ampliamente en el siguiente capítulo) y también morales, para poder enseñar y ejercer control, tanto moral como intelectualmente sobre sus estudiantes. En otras palabras, para estar facultado para controlar, el docente tiene que conocer y tener ciertas calidades morales. No es válido para el maestro poseer 
solo una de las dos características (intelectuales o morales), debe poseer ambas. Descartes dijo en la «Carta prefacio» que

I' ay pris garde, en examinant le naturel de plusieurs esprits, qu' il n' y en a presque point de si grossiers ny de si tardifs, qu' il ne fussent capables d'entrer dans le bons sentimens y mesmes d' acquerir toutes les plus hautes sciences, s' ils estoient conduits comme il faut ${ }^{43}$ (A.T., IX-2, 12; 18-23).

Durante el desarrollo de este capítulo he ido confirmando que la preocupación moral no es un asunto periférico, sino primordial en el pensamiento de Descartes. El desarrollo moral del individuo se convierte en un objetivo de máxima atención en Descartes, por cuanto su filosofía atañe al hombre y al mundo en una estrecha unidad.

Los seres humanos en tanto somos seres capaces de moralidad, podemos dar y pedir razones morales. Somos sujetos morales y Descartes lo sabía perfectamente. Ahora bien, para el genio francés estas personas generosas serían las llamadas a cumplir el crítico e importantísimo papel de maestros y guías para aquellos quienes no posean las calidades intelectuales ni morales para guiarse a sí mismos y alcanzar su máximo potencial mediante la educación. Desde luego, este máximo potencial dependerá de cada persona y del desempeño que se ponga en el mayor autocontrol posible.

Además de comprender el lugar de privilegio que tiene la filosofía moral en Descartes, este apartado también confirma que la filosofía moral cartesiana da pie al control de unos seres humanos sobre otros. Este control parece ser completamente bien intencionado y benevolente, pero control al fin. Desde luego los alcances últimos a los que pudiera dar pie este control están fuera del ámbito de influencia del filósofo, quien sin ningún mal propósito lo pensó así.

\section{Referencias}

Adam, C y Tannery, P. (1996). OEuvres de Descartes. Paris: Libraire philosophique J. Vrin. Tomos I- XI.

43 «He apreciado, al examinar lo natural de diversos espíritus, que no los hay tan rudos ni tan torpes que no fueran capaces de nobles sentimientos y mismos de adquirir todas las más altas ciencias si fueran conducidos correctamente». 